\title{
Oxyhydroxide hydrothermal crusts from Saldanha hydrothermal field
}

\author{
Pedro Costa ${ }^{1}$ AND ÁgAta Alveirinho Dias ${ }^{2}$
}

${ }^{1}$ Institute of Science and Environment (ISE), University of

Saint Joseph, Macao SAR; 201800459@usj.edu.mo

${ }^{2}$ Institute of Science and Environment (ISE), University of

Saint Joseph, Macao SAR; agata.dias@usj.edu.mo

The Saldanha hydrothermal field is located at the top of a mount in the Mid-Atlantic Ridge (MAR, $36^{\circ} 34^{\prime} \mathrm{N}, 32^{\circ} 26^{\prime} \mathrm{W}$, $2200 \mathrm{~m}$ ). The field is covered by pelagic sediment from where transparent and weak fluids vent through small orifices. Oxyhydroxides $(\mathrm{OH})$ occur mainly within the top of that sediment cover, forming crusts containing millimetric microchimneys.

In this work, the mineralogy and geochemistry of Saldanha $\mathrm{OH}$ crusts were studied using X-ray diffraction (XRD), Electron microprobe (EPMA), Scanning Electron Microscopy / Energy Dispersive X-Ray Spectroscopy (SEM/EDS) and geochemical (INAA, ICPMS) analysis.

Saldanha crusts show a zoned pattern with alternate thin layers of acicular oxyhydroxides with massive cryptocrystalline oxides. Mineralogical and textural observations collectively indicate an open space setting for the growth of the oxyhydroxide minerals within the sediment cover.

Although these phases are Mn-rich in composition, large variation on $\mathrm{MnO}_{2}(46-83 \mathrm{wt} \%), \mathrm{MgO}(5-24 \mathrm{wt} \%)$ and $\mathrm{FeO}$ (usually less than $1 \%$ ) content was noted. Todorokite and birnessite form the more massive and crystalline phases and display the higher contents in Mn. Vernadite, on the other hand, form elongated structures and microconcretions (botryoidal textures) identified in the acicular layers. This less crystalline phase displays a higher content in $\mathrm{MgO}$.

Geochemical discriminant diagrams revealed a hydrothermal origin for these $\mathrm{OH}$ phases. However, $\mathrm{Mg}$ and part of $\mathrm{Mn}$ might be derived from seawater due to an extensive mixing between the ascendent hydrothermal fluid and the descendent seawater.

In conclusion, Saldanha crusts were precipitated at the sediment cover in the upper part of the hydrothermal system, as consequence of more oxidizing conditions. The depletion in $\mathrm{Fe}$ content in these phases can be explained by the precipitation of this metal in the form of sulphides, found in deeper parts of the system. 